
\title{
R Reserach S Suare \\ Phenotyping of boro rice (Oryza sativa L.) cultivars in Assam based on its potential yield and variable component traits
}

\section{Amit Kumar Pradhan}

Gauhati University

Bhaben Tanti ( $\sim$ btanti@gauhati.ac.in )

Gauhati University https://orcid.org/0000-0002-7594-4562

\section{Research Article}

Keywords: boro rice, cultivar, grain yield, component traits, flood, sali rice

Posted Date: December 14th, 2021

DOI: https://doi.org/10.21203/rs.3.rs-1151795/v1

License: (c) (1) This work is licensed under a Creative Commons Attribution 4.0 International License.

Read Full License 


\section{Abstract}

The current environmental scenario and increased average yield rate has marked boro rice cultivars as a potent rice cultivar during rabi season. It serves to be an alternative to traditional sali rice and an escape to flood problems. The selection and development of potent boro rice cultivar among its diverse types has been an issue. In this study, 117 traditionally grown boro rice cultivars in different low-lying areas and newly developed irrigated areas of Assam were analyzed. The cultivars were analyzed based on yield and related component traits as per the standard evaluation system for rice. Grain yield and its related component traits showed a significant relationship among the cultivars. All the traits analyzed showed positive relationship with grain yield and harvest index except to time taken for flowering and maturity. Based on total yield, principal component and cluster analysis, Bahurupi, PSB 68, Mandhya Vijaya, Bahunipi, Pathariya showed to be best performing cultivars, with high yield and higher component traits performance. This study marks the significant association of grain yield with its component traits and further provides an insight to the selection of rice cultivars for breeding programmes.

\section{Introduction}

Rice (Oryza sativa L.) is one of the most staple foods of more than three billion people in the world. It is the leading food source in terms of calories being consumed by mankind and feeds about $60 \%$ of the world's population (FAO 2007). With the advancement in agricultural techniques, the productivity of rice is increasing at a rate of $1 \%$ per year. But as per recent reports, the required rate of rice production has reached 2.4\% per year to meet the global need (Varshney et al. 2011).

Among all the rice growing continents in the world, Asia alone produces about $95 \%$ of the world's rice that contributes to $40-80 \%$ of the calorie intake (Bagheri et al. 2013). India is also one of the highest rice producing countries in the world which supplies nearly half of the total world rice production (Anonyms 2012). Assam state, in Northeast (NE) India with dynamic climatic and physiographic features offers favorable conditions for rice cultivation. Rice is grown in a wide range of agro-ecological situations. Assam is one of the major rice growing state in India and possess a huge number of rice cultivars with many unexplored wild varieties. About $70 \%$ area of the total agricultural fields or arable lands in Assam are being occupied by the rice cultivation (Singh et al. 2015; Lal et al. 2013).

Diverse environmental conditions in Assam have resulted into three distinct rice growing seasons viz. ahu (February /March - June /July), sali (June /July - November /December) and boro (November /December -May /June). In general, ahu and boro season are also termed as rabi season and sali as kharif season. Rice grown in ahu season are known as autumn rice so as in Sali as winter and those in boro as summer rice. Summer rice is mostly known as boro rice.

Boro rice is a photo-insensitive crop traditionally grown in low-lying areas. It is well known for the high productivity (5-6 t/ha) in deep-water areas of Eastern India, where productivity has traditionally been very poor ( $<1 \mathrm{t} / \mathrm{ha})$ during the kharif season. In Assam, boro rice cultivation is restricted mainly to three 
different zones, viz., the central Brahmaputra valley, the lower Brahmaputra valley, and the Barak valley Zone covering only 0.15 million ha area of the state's total arable area of 2.5 million ha (Singh et al.2003; Pathak et al. 2000). But, in comparison to the area it is cultivated, higher and better productivity has been recorded (Das et al. 2015; Ahmed et al. 2011). As per 2006-2016 rice production statistical report of Assam, average yield of boro rice reported a regular increase as compared to the largely cultivated traditional sali rice and autumn rice (Statistical handbook of Assam; Report by Directorate of Economics and Statistics, Assam 2003-2013) (Fig. S1).

In the current agricultural environmental scenario, flood and soil erosion has become a major drawback for rice cultivation. Though Assam along with other NE states, is known for high amount of rainfall but rainfall alone does not stand as the only reason for flood in Assam (Rehman et al. 2021; Rasid et al. 2019). The big river dams increase in soil exploitation viz., removal of sands, gravels from the river surrounding's, large occupancy of river side areas has now appeared to be a major factor causing flood and soil erosion. These factors have highly caused the increase in water level or river water tide that surpasses embankments and submergence of cultivation areas (Bandyopadhyay et al. 2015; Mandal 2010; Goyari 2005).

In Assam, majority of the farmers dwell upon river water for rice cultivation. Flood in Assam mainly occurs during the early sali season in Assam i.e., June-August, the time for sali/ winter rice transplant or sowing. Thereby, during the traditional rice growing season of Assam (sali season), most of the low-lying areas remain submerged under water (Ahmed et al. 2011; Pathak et al. 2000). On the other hand, during boro season, flood factor appears to be minimal with low rainfall and areas suitable for boro rice cultivation (such as low-lying areas) with adequate amount of water accumulated during monsoon. Boro rice cultivation during the boro season along with flood free condition thereby appears to be a better option for higher production. Cultivation of boro also provides various other advantageous factors such as - (a) low insect-pest infestation during the growth phase; (b) low winter temperature during the vegetative phases that favors higher accumulation of photosynthates leading to increase in C: $\mathrm{N}$ ratio and (c) the ripening phase falling in the pre-summer condition facilitates early ripening with rise in temperature (Singh 2002). Various studies also reported, boro rice with few other significant characters such as better uptake of fertilizers, cold tolerant etc., which serves to be an advantage for better yield (Talukdar and Beka, 2005; Patra et al. 2003). Thus, boro rice may serve to be an alternative for rice cultivation as majority of the people dwell upon rice cultivation for food and economy (Rehman and Tanti, 2021).

Though, boro rice in Assam has gathered an upward spike in yield and growth with the upgradation in irrigation and greater interest among the farmers. The selection of cultivars remains a huge concern among the farmers with large number of traditional as well high yielding varieties (Pande et al. 2006). Traditional cultivars are known to be the reservoir of various influential traits that can withstand many harsh stress conditions (Barah 2006). Traditional cultivars have also been reported to show a better trait as compared to the high yielding varieties. High yielding varieties are mainly developed with targets to a specific condition for high productions but conditions beyond causes the constraint/ stagnancy in its 
production. Therefore, an attempt has been made to understand the traditional and high yield boro cultivars of Assam for better selection based on their yield and component traits. Analysis of yield and its related components traits helps determine the ability of rice to transform vegetative biomass into grains.

\section{Materials And Methods}

Plant materials and field experiment

A field experiment was conducted with 117 traditionally grown boro rice cultivars of Assam. The rice cultivars were collected from different low-lying areas and newly developed irrigated cultivation areas of Assam. The experiment was conducted in two boro season viz. $2018-2019$ and $2020-2021$. The first experiment was conducted at Regional Rainfed Lowland Rice Research Station (RRLRRS) under National Rice Research Institute (NRRI), Gerua, Assam and second in a normal cultivation field at Pathsala under Bajali district Assam. The experiment was laid out in a randomized block design (RBD) with three replications. The well germinated rice seedlings of all the cultivars were transplanted into well puddled raised nursery seed bed as per standard guidelines from International Rice Research Institute (IRRI). The seedling was allowed to grow till four-five leaf stage or height of $15-20 \mathrm{~cm}$. The seedlings were then transplanted to well puddled experimental field with $20 \times 20 \mathrm{~cm}^{2}$ gap among the hill and a gap of $50 \mathrm{~cm}$ between the two cultivars. The chemical fertilizers like Urea, TSP, MOP and Gypsum were applied as 215 $\mathrm{kg}, 180 \mathrm{~kg}, 100 \mathrm{~kg}$, and $20 \mathrm{~kg}$ per hectare, respectively. At the beginning of land preparation one half of urea, full dose of TSP, MOP and gypsum were applied to the experimental plot. The remaining half of urea was applied in two splits, one at tillering and other at booting stages. After one week, in some plots, gaps of missing seedling were filled with the stock seedlings. Intercultural operations such as weeding by hand picking and applications of pesticides by hand sprayer at the vegetative growth stages were done as and when necessary. The water level was also monitored regularly.

\section{Phenotyping}

Evaluation and collection of data of the cultivars for yield and its component traits were performed as per the Standard Evaluation System for Rice by IRRI. The parameters and methodology used for the evaluation includes- days to $50 \%$ flowering, days to maturity, plant height, effective tillers per plant, panicle length, panicle weight, number of spikelets per panicle, percentage of filled spikelet, spikelet fertility, test grain weight, biological yield per plant, grain yield per plant and harvest index.

The rate of flowering was recorded by measuring the period of time after transplant viz., date of sowing to emergence of panicle in 50 percent of the plants of a particular cultivar. The total days to maturity was recorded by counting days to harvest of the cultivar from sowing. Height of the plant was measured using standard measuring scale from ground to tip of the panicle (excluding awn). Number of effective tillers per plant was counted at the time of maturity. Panicle length, panicle weight, spikelet per panicle and percentage of filled panicles was measured and counted by randomly picking 15 panicles from each cultivar in three replicates. 
Percentage of filled spikelets per panicle was measured using the standard formula established by IRRI,

$$
\% \text { offilledspiklets } / \text { panicle }=\frac{(\text { Totalnumberoffilledspiklets } / \text { panicle })}{(\text { Totalnumberofspiklets } / \text { panicle })} \times 100
$$

Spikelet fertility was determined based on the filled fertile spikelets and the cultivars were differentiated based on the following scale: Highly fertile $(>90 \%)$, fertile (75-89\%), partly sterile (50-74\%), highly sterile ( $<50 \%$ to trace) and $0 \%$ fertile (SES, IRRI (2013).

Test grain weight was measured by weighing 1000 grain weight in grams. Yield of the plant was evaluated based on the biological and grain yield per plant. Biological yield was measured by weighing the total dry weight of above ground portion of the plant. Grain yield of the plant was measured after the harvest by thrashing the grains and weighing after drying to $12 \%$ moisture content.

Harvest Index was calculated as the ratio of economic yield to the total biological yield and expressed in percentage using the following formula-

$$
\text { HarvestIndex }(\%)=\frac{\text { Economicyield }}{\text { Biologicalyield }} \times 100
$$

\section{Data analysis}

All data analysis were carried out in R program. The Performance Analytics package of $\mathrm{R}$ was used to plot the correlation analysis. The Complex Heatmap package was used to for clustering and heatmap. FactoMineR and factoextra were used to visualized the principal component analysis results. In addition, the ggplot2 package was used for graphical representation.

\section{Results And Discussion}

Days to flowering and maturity

Flowering refers to opening and closing of floret followed by panicle exertion and heading (Slaton 2011). Days to $50 \%$ flowering and days to maturity represents the time period taken by plants from sowing to maturity (Ranawake et al. 2014). Of the 117 boro rice cultivars studied, V1 Nagaon took the highest days to $50 \%$ flowering (132 days) and maturity (296 days) whereas Luit took the lowest days to flowering (57 days) and maturity (153 days) (Fig. 1). Luit cultivar thereby, may be considered a better cultivar in terms of days to maturity as, rice plants with minimum days to flowering and maturity indicates to be a better cultivar (Ranawake et al. 2014). As per IRRI, rice cultivars within the range 105-120 days to maturity are termed to be short duration cultivars and beyond 150 days as long duration cultivars (IRRI 2013). In this study, it is found that the boro rice is a long duration rice cultivar. Maturity of boro rice before the onset of monsoon prevents rice from loss of grain and yield (Singh 2002). It has been reported that the cold temperature during the vegetative stage, leads to higher time period for flowering and maturity (Rehman and Tanti 2021; Priyanka et al. 2015). 


\section{Plant height}

The maximum height was observed in Kasturi $(135 \mathrm{~cm})$ and the lowest in case of CSR 27 (64 cm) (Fig. S2). According to IRRI (2013), the plant height is divided into three categories, namely short $(<110 \mathrm{~cm})$, medium $(110-130 \mathrm{~cm})$, and tall $(>130 \mathrm{~cm})$. In this study, based on the categorization by IRRI, 82 cultivars have short height, 30 cultivars with medium height and 5 cultivars with tall height. The medium cultivars are reported to be best suited cultivars for high yield and production (Singh et al. 2015). Rice cultivars with tall height undergoes lodging leading to loss in grain yield. Cultivars with short height also fail to hold good number of tillers by which spikelets fall. But medium height cultivars best suits to hold good number of tillers with filled spikelets and give a good grain yield (Donde et al. 2020; Ma et al. 2016; Roy et al. 2014)

Number of effective tillers per plant

The number of effective tillers represent the number of panicles in a plant bearing the spikelets/grains. The number of effective tillers per plant signifies the potential yield of a cultivar. Cultivars with high effective tillers are marked to possess high tillering ability (Karki et al. 2018; Feng et al. 2007). Cultivar with good tillering ability directly correlates to its grain yield (Ratna et al. 2015; Akinwale et al. 2011). Pathariya rice cultivar with 36 number of effective tillers showed the highest number of effective tillers. But Anjali, China boro, CRL-141, CRL-194 and Jhum Dhan with 07 effective tillers showed the lowest number of effective tillers. According to IRRI (2013), cultivars with effective tillers, more than 25 per plant has been termed to possess high tillering ability. Based on the number of effective tillers, the tillering ability has been classified as follows: 20-25 tillers per plant as good tillering, 10-19 per plant as medium, 5-9 per plant as low and below 5 per plant as very low tillering ability. In this study, 32 cultivars possess low tillering ability, 34 with medium ability, 41 cultivars with good ability and 10 cultivars with high tillering ability (Fig. S3).

\section{Panicle length}

Panicle length of rice cultivars marks to be a significant component trait for good yield. Rice cultivars with long panicles directly indicate high number of total spikelets/grain and high yield (Takai et al. 2019; Sheehy et al. 2001). A concurrent positive relationship has been observed among the traits viz., number of spikelets per panicle and 1000 grain weight with the panicle length (Prasad et al. 2015). Of the 117 boro rice cultivars studied, panicle length ranged between $17-31 \mathrm{~cm}$ respectively. No. 15 Aijung with 17 $\mathrm{cm}$ showed the shortest panicle length and Ananda rice cultivar showed the longest panicle length of 31 cm (Fig. S4).

\section{Panicle Weight}

Panicle weight of a rice cultivars correlates to the panicle length and total spikelets per panicle. High panicle weight determines cultivars with high yield and production. In this study, highest panicle weight was observed in Govindh cultivar (4.56 g) and lowest in No. 15 Aijung (0.77 g) (Fig. S5). 
The number of filled spikelets per panicle represents total number of spikelets subtracted from non-filled spikelets. The filled spikelets per panicle serves as a major component trait that signifies the productivity of rice (Nandini et al. 2017; Kato 2004). The number of filled spikelets per panicle ranged from 43 to 232. Jaldi dhan-6 with 43 filled spikelets in average showed the lowest number and Mandhya vijaya (232) showed the highest number of filled spikelets (Fig. S6). The number of filled spikelets in comparison to the total spikelets also indicates fertility of cultivar.

Spikelet fertility

The no. of filled spikelet out of total spikelet in a panicle represents spikelet fertility and, the fertility of cultivar. Higher filled spikelet means highly fertile cultivar. As per IRRI (2013), cultivars with percentage of spikelet fertility above $90 \%$ has been marked as highly fertile, $75-89 \%$ as fertile, $50-74 \%$ as partly sterile and below $50 \%$ as highly sterile. Among the 117 cultivars studied, two cultivars Asu boro (91\%) and Sali boro (91\%) showed high fertility, 46 cultivars appeared to be fertile, 61 cultivars as partly sterile and remaining 8 as highly sterile (Fig. S7).

Test grain weight

Test grain weight or 1000 grain weight signifies the quality of grain developed by a cultivar. Higher grain weight provides better grain quality leading to increased yield of cultivar. Grain weight represents the rate of grain filling and the grain size at the time of maturation. Bahurupi $(38.4 \mathrm{~g})$ showed the highest grain weight and Heera $(9.2 \mathrm{~g})$ the lowest. An average of $19.1 \mathrm{~g}$ test grain weight was observed among the cultivars studied (Fig. S8).

Grain yield per plant

High grain yield of rice cultivar is the important trait for high yielding cultivar or developed crop. Grain yield per plant in correlation to its component traits signifies the final yield of the cultivar after harvest. Grain yield includes the weight of grains at $14 \%$ moisture. Grain yield highly correlates to no. of effective tillers, no. of filled grains and grain weight. The higher weight and higher number of filled grains gives high grain yield per plant. Of 117 cultivars, Bahurupi $(92.27 \mathrm{~kg})$ showed the highest grain yield followed by PSB 68 (85.2 g), Buhunipi (79.94 g), Pathariya (76.71 g), Mandhya Vijaya (76.06 g), Kavya (75.13 g) which grain yield above $75 \mathrm{~g}$. VLD $65(4.72 \mathrm{~g})$ showed the lowest grain yield (Fig. 2). Grain yield of a cultivar varies among the rice cultivars based on various genetic and environmental factors (Prasad et al. 2015). Grain yield of a cultivar completely depends on its overall performance. Cultivars with changes in other traits like increase in plant height, decrease in panicle length or less no. of filled spikelets decreases the yield of cultivar (Donde et al. 2020; Jabeen et al. 2018; Okamura et al. 2018; Akter et al. 2014).

Biological yield per plant 
Biological yield refers to the total dry weight of the above ground portion of the plant except the grain containing panicle. It indicates the total growth weight showing the strength of the plant. Higher biological yield signifies better yield with high number of spikelets. In this study, pant Sugandh showed the highest biological yield $(70.28 \mathrm{~g})$ and Garia showed the lowest with $13.72 \mathrm{~g}$ in average (Fig. S9).

Harvest index

Harvest index refers to the measure of cultivars capability in partitioning assimilated photosynthate. Increase in harvest index refers to the increase in yield of a cultivar (Jabeen et al. 2018; Li et al. 2012). It represents the ratio of grain yield to that of biological yield expressed in percentage. Harvest index measurement provides complete yield of cultivar after maturity. Higher percent of harvest index indicates better grain yield. Pathariya (77.82\%) and Bahurupi (77.03\%) showed the highest harvest index followed by Kavya (76.36\%), Kasturi (74.23\%) accordingly. V1 Nagaon (21.55\%) cultivar showed the lowest harvest index (Fig. S10).

Correlation analysis of yield and its component traits

Yield is a complex trait, determined by the interaction among its component traits. Selection for the increase in yield of a cultivar is not based completely on its grain yield because of its complexity and relationship with other yield components. Therefore, a correlation between yield and its component traits reveals the capability of a cultivar for high productivity. The correlation analysis of the total grain yield and component traits of the 117 boro rice cultivars represented a significant relationship between them. Days to $50 \%$ flowering $\left(-0.96^{\star \star *}\right)$ and maturity $\left(-0.97^{\star * *}\right)$ showed a significant negative relationship with all other yield related traits (Prasad et al. 2015; Ranawake et al. 2014). As increase in flowering time and maturity increases the time period for harvest which causes loss in yield. Effective tillers per plant, panicle weight, total spikelets per panicle, test grain weight (1000 grain weight) and biological yield showed significant positive relationship with grain yield and overall harvest index (Ratna et al. 2015; Akinwale et al. 2011). This positive relationship shows its significance in the increase of grain yield of a cultivar. The traits with positive significance with yield also showed positive correlation amongst them such as the no. of effective tillers significantly correlated with panicle weight $\left(0.87^{\star \star \star}\right)$, total spikelets per panicle $\left(0.75^{\star \star}\right)$ and biological yield (0.89***) (Fig. 3). Overall, the grain yield significantly correlated to the harvest index $(0.99 \star \star \star)$, showing good grain yield as indicator to good harvest index (Okamura et al. 2018; Li et al. 2012).

Principal component analysis

In this study, the principal component analysis (PCA) was performed for twelve yield and its related component traits of boro rice cultivars. The PCA analysis revealed that three principal components with eigen values $>1$ capturing $45.83 \%$ of the cumulative variation. The Principal Components (PC) viz., PC1, PC2 and PC3 represented higher variance percentage of $45.83,17.64$ and $9.42 \%$ respectively. PC2 was greatly influenced by traits- plant height, panicle length, test grain weight, total spikelets per panicle, panicle weight, grain yield and harvest index to the positive end and no. of effective tillers, biological yield 
and filled spikelets per panicle towards the negative end. The PC2 traits clearly indicates cultivars showing good phenotypic yield as observed in phenotypic data individually (Fig. 4a, b). The cultivars included in PC2 may be taken for further breeding programme and cultivar improvement (Beena et al. 2021; Li et al. 2012).

Clustered analysis of the cultivars based on its yield and related traits

Based on the principal component analysis, a clustered analysis was further performed with the traits included in PC2 to check complete performance of cultivars in ranking pattern (Donde et al. 2020). Clustered analysis was performed taking the traits included in PC2 i.e. - plant height, panicle length, test grain weight, total spikelets per panicle, panicle weight, grain yield and harvest index. As marked in PC2, clustered analysis clearly revealed cultivars Bahurupi, PSB 68, Mandhya Vijaya, Buhunipi and JGL 3844 as the top performing cultivars and cultivars such as No. 15 Aijung, Sahbhagi dhan marked in PC1 as low performing cultivars (Fig. 5).

\section{Conclusion}

The higher grain yield of rice cultivar clearly indicated the significance of its related traits. Cultivars with overall better performance i.e., better yield related traits showed high grain yield. Out of the 117 cultivars, evaluated in this study based on PCA and cluster analysis, Bahurupi showed to be the most suitable cultivar followed by PSB 68, Mandhya Vijaya, Bahunipi, Pathariya respectively. The cultivars indicated under grain yield, harvest index showed the same cultivars as like that of PCA and cluster. Bahurupi showed the best overall performance in comparison to other cultivars based on grain yield and its component traits. The top performing cultivars among the cultivars studied, showing better grain yield along with its component traits will provide an insight to rice breeders for further enhancement and develop better yielding boro rice cultivar.

\section{Declarations}

Acknowledgements We highly acknowledge Dr. Rupankar Bhagawati and the members of RRLRRS, Gerua, Assam for helping us in experimental set up and technical assistance. We also thank Preetom Regon for the technical support in performing the data analysis. We also acknowledge DST-FIST, Govt. of India for the sponsored infrastructural facilities in the Dept. of Botany, Gauhati University.

Author contributions Pradhan AK: manuscript design, conduct of experiment, analysis, manuscript writing and editing; Tanti B: experimental design, editing, writing and supervision.

Conflicts of interest The authors declare no conflict of interest.

Data availability statement The Data used in this study, are composed of primary data obtained from experimental analysis. Data have been clearly represented within the manuscript in graphical and tabular 
forms. Further raw data which support this study will be shared upon reasonable request to the corresponding author.

\section{References}

1. Ahmed T, Chetia SK, Chowdhury R, Ali S (2011) Status paper on rice in Assam. Directorate of rice research, Hyderabad: Rice State Wise 1-49

2. Akinwale MG, Gregorio G, Nwilene F, Akinyele BO, Ogunbayo SA, Odiyi AC (2011) Heritability and correlation coefficient analysis for yield and its components in rice (Oryza sativa L.). Afr J Plant Sci 5(3):207-212

3. Akter S, Hossain M, Huda A, Islam MR, Jahiruddin M (2014) Evaluation of growth, yield and nutrient content of some Boro rice cultivars. Res Agric Livest Fish 1(1):19-25

4. Anonyms, Food and agriculture organization of the United Nations FAOSTAT (2012) Food and Agriculture Organization of the United Nations. .2012

5. Bandyopadhyay S, Reza SK, Dutta DP, Baruah U, Sah KD, Singh SK (2015) Development of integrated land use plan for Upper Brahmaputra Valley under rain-fed ecosystem: A case study in Jorhat district. Assam Agropedology 25(2):181-194

6. Barah BC (2006) Agricultural Development in North-East India Challenges and Opportunities

7. Beena R, Kirubakara S, Nithya N, Manickavelu A, Sah RP, Abida PS et al (2021) Association mapping of drought tolerance and agronomic traits in rice (Oryza sativa L.) landraces. BMC Plant Biol 21(1):1-21

8. Das S, Sarma D, Kalita P (2015) Morpho-physiological variability in boro rice (Oryza Sativa L.). Bioscan9 1: 611-619

9. Donde R, Mohapatra S, Baksh SY, Padhy B, Mukherjee M, Roy S et al (2020) Identification of QTLs for high grain yield and component traits in new plant types of rice. PLoS ONE 15(7):e0227785

10. FAO (2007) Agriculture Organization of the United Nations, Rome; 2007. Series 38 Last Accessed Nov. 2013, ISBN 978-92-5-105750-6

11. Feng W, Cheng FM, Zhang GP (2007) Difference in grain yield and quality among tillers in rice genotypes differing in tillering capacity. Rice Sci 14(2):135-140

12. Goyari P (2005) Flood damages and sustainability of agriculture in Assam. Econ Political wkly27232729

13. IRRI (2013) Standard evaluation system for rice, 5th edn. IRRI, Manila, The Philippines

14. Jabeen Z, Irshad F, Shah SMA, Hussain N (2018) Genotypic Evaluation of Different Rice Varieties for Yield and Yield Related Traits. J Rice Res 6(199):2

15. Karki S, Poudel NS, Bhusal G, Simkhada S, Regmi BR, Adhikari B, Poudel S (2018) Growth parameter and yield attributes of rice (Oryza sativa) as influenced by different combination of nitrogen sources. World J Agric Res 6(2):58-64 
16. Kato T (2004) Effect of spikelet removal on the grain filling of Akenohoshi, a rice cultivar with numerous spikelets in a panicle. J Agri Sci 142(2):177-181

17. Lal B, Gautam P, Panda BB, Raja R (2013) Boro rice: a way to crop intensification in Eastern India.Pop kheti1(1)

18. Li X, Yan W, Agrama H, Jia L, Jackson A, Moldenhauer K et al (2012) Unraveling the complex trait of harvest index with association mapping in rice (Oryza sativa L.). PLoS ONE 7(1):e29350

19. Ma X, Feng F, Wei H, Mei H, Xu K, Chen S, Luo L (2016) Genome-wide association study for plant height and grain yield in rice under contrasting moisture regimes. Front Plant Sci 7:1801

20. Mandal R (2010) Cropping patterns and risk management in the flood plains of Assam. Econ Political wkly $78-81$

21. Nandini B, Gangappa E, Rajanna MP, Mahadevu P, Ramesh S, Hittalmani PS (2017) Genetic variability analysis for grain yield and its components traits in traditional rice varieties (TRVs). Int $J$ Curr Microbiol Appl Sci 6(8):494-502

22. Okamura M, Arai-Sanoh Y, Yoshida H, Mukouyama T, Adachi S, Yabe S et al (2018) Characterization of high-yielding rice cultivars with different grain-filling properties to clarify limiting factors for improving grain yield. Field Crops Res 219:139-147

23. Pande K, Singh S, Singh ON (2006) Stability of rice (Oryza sativa L.) varieties for boro season of eastern India. Indian J Gen Plant Breed 66(3):191-195

24. Pathak PK, Saud RK, Bora DK, Singha KD, Pathak AK (2000) Status of Boro (summer) rice in Assam: A case study. International Rice Commission Newsletter (FAO)

25. Patra BC, Pande K, Samsudeen K (2003) Exploration of boro rice germplasm in Assam.Plant Genet Resour NewsI58-60

26. Prasad KR, Krishna KVR, Bhave MHV, Rao LVS (2015) Correlation and path coefficient analysis for yield and yield component traits in boro rice (Oryza sativa L.). Int J Trop Agric 33(2):735-740

27. Priyanka K, Jaiswal HK, Waza SA, Sravan T (2015) Response of rice seedlings to cold tolerance under boro conditions. SABRAO J Breed Gen 47(2):185-190

28. Ranawake AL, Amarasinghe UGS, Hewage MJ, Pradeepika NGJ (2014) Effect of days to flowering on plant height and yield of rice (Oryza sativa L.). Int J Plant Soil Sci 3(9):1143-1152

29. Rasid N, Prashnani M, Goswami J, Raju PLN (2019) Crop Damage Assessment in Flood Inundated Area of Morigaon District of Assam. Int Arch Photogramm Remote Sens Spat Inf Sci

30. Ratna M, Begum S, Husna A, Dey SR, Hossain MS (2015) Correlation and path coefficients analyses in basmati rice. Bangladesh J Agric Res 40(1):153-161

31. Rehman M, Tanti B (2021) Screening of boro rice varieties of Assam, India to estimate their potential resistance to cold and heat stresses.Vegetos 1-15

32. Rehman M, Jyoti SY, Pradhan AK, Regon P, Tanti B (2021) Characterization of boro rice (Oryza sativa L.) varieties of Assam (India) based on their morphological traits. Int J Bot Stud 6(5):1051-1062 
33. Roy SK, Ali MY, Jahan MS, Saha UK, Ahmad-Hamdani MS, Hasan MM, Alam MA (2014) Evaluation of growth and yield attributing characteristics of indigenous Boro rice varieties. Life Sci J 11(4):122126

34. Sheehy JE, Dionora MJA, Mitchell PL (2001) Spikelet numbers, sink size and potential yield in rice. Field Crops Res 71(2):77-85

35. Singh CS, Singh MOHIT, Singh SK, Singh AK, Singh AK (2015) Growth and yield response of rice cultivars under system of rice intensification and conventional method of rice production system. Ecoscan 9(3-4):1077-1081

36. Singh S, Routaray S, Singh UD, Singh RK (2003) In: Thakur MR (ed) Boro rice in Assam: Status and strategy for higher productivity. Boro rice (Singh, Rk, Hossain. IRRI-India Office, pp 83-97

37. Singh UP (2002) Boro rice in eastern India. In Rice-wheat consortium regional technical coordination committee meeting, pp 10-14

38. Slaton N (2011) Rice production handbook. University of Arkansas, United States Department of Agriculture

39. Statistical Handbook of Assam (2014) - Published by Directorate of Economics and Statistics, Assam State/District Wise Area, Production, Price and Value of the Major Crops in Assam from 200304 To 2012-13 -Published by. Directorate of Economics and Statistics, Assam

40. Takai T, Lumanglas P, Simon EV, Arai-Sanoh Y, Asai H, Kobayashi N (2019) Identifying key traits in high-yielding rice cultivars for adaptability to both temperate and tropical environments. Crop $\mathrm{J}$ 7(5):685-693

41. Talukdar KC, Beka BC (2005) Cultivation of summer rice in the flood plains of Assam - An assessment of Economic Potential on marginal and small farms. Agric Econ Res Rev 18:21-38

42. Varshney RK, Bansal KC, Aggarwal PK, Datta SK, Craufurd PQ (2011) Agricultural biotechnology for crop improvement in a variable climate: hope or hype? Trends Plant sci 16(7):363-371

\section{Figures}

\section{Figure 1}

Stacked barplot representing the days to $50 \%$ flowering and maturity. The value on each bar represents the number of average days of 3 biological replicates.

\section{Figure 2}

Barplot indicating the total grain yield per plant of the boro rice cultivars studied in decreasing order. The error bar represents standard error of mean values performed with minimum of 3 biological replicates. 


\section{Figure 3}

Correlation analysis among the yield and its related component traits. The correlation plot was prepared by PerformanceAnalytics package of $\mathrm{R}$. The distribution of each variable is shown on the diagonal. On the bottom of the diagonal: the bivariate scatter plots with a fitted line are displayed on the top of the diagonal: the value of the correlation plus the significance level as stars. Each significance level is

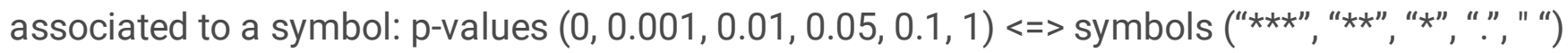

\section{Figure 4}

Principal component analysis among the yield and its component traits. a) Scree plot representing the percentage of variance of the principal components based on eigen values; b) Biplot showing the PCA 1 and PCA 2

\section{Figure 5}

Heatmap of boro rice cultivars based on grain yield, harvest index, panicle length, panicle weight, total spikelets and filled spikelets. The value of each trait was log transformed and heatmap was constructed. Heatmap was ranked by hierarchical clustering performed using ComplexHeatmap package of R.

\section{Supplementary Files}

This is a list of supplementary files associated with this preprint. Click to download.

- SupplementaryFigureswithlegends.docx 